\title{
Air layering in nutmeg (Myristica fragrans Houtt.)
}

\author{
V A M Nissar*, B Sasikumar ${ }^{1}$, S Aarthi \& J Rema \\ Division of Crop Improvement and Biotechnology \\ ICAR-Indian Institute of Spices Research, Kozhikode-673 012, Kerala. \\ *E-mail: muhammednissar@gmail.com
}

Received 24 August 2018; Revised 10 May 2019; Accepted 24 June 2019

\begin{abstract}
Nutmeg is an important perennial spice crop, which is dioecious in nature. Vegetative propagation is the norm in commercial propagation of the tree. The existing practice of propagation is grafting and budding which needs good skill and expertise for reasonable success. As an alternative to these two methods, air layering was attempted in matured trees for the first time in the country. Air layering was successful in plagiotropic and orthotropic shoots with 100 per cent survival. This method is cost effective and is easy for adoption.
\end{abstract}

Keywords: air layering, Myristica fragrans, nutmeg, propagation

Nutmeg (Myristica fragrans Houtt.) is an important tree spice native to Moluccas islands of Indonesia, introduced to India during the 18 century. Nutmeg is now grown in around 20,000 ha in the country. Nutmeg is dioecious in nature and yields two spices, the seed or kernel and the aril or mace. Male trees are unproductive. Commercial plantations are raised mostly using grafts or buds to circumvent the sex problem. A ratio of 1:10 male: female trees are recommended in the plantations. Currently, femaleness is ensured by grafting or budding, which needs good skill and experience for reasonable success. The dimorphic branching pattern of the tree is another issue of relevance in case of vegetative propagation. The scions or buds extracted from the orthotropic shoots only exhibit vigorous erect growth and canopy development similar to the seedling trees and the availability of such scions from mother trees is limited. Hence, commercial nurseries generally propagate nutmeg through budding rather than grafting as the bud-wood provides maximum numbers of orthotropic propagules. However, the success rate in budding is a matter of skill, experience and season and hence budded plants are priced very high by the nurseries.

Air layering as a cost effective and easy method of propagation in nutmeg is not attempted

${ }^{1}$ Formerly Principal Scientist \& Head, Division of Crop Improvement \& Biotechnology, ICAR-Indian Institute of Spices Research, Kozhikode-673 012, Kerala. 
seriously in India, though there are reports of limited success and failed field establishment in Grenada, West Indies and New Guinea. In New Guinea, about $60 \%$ rooting was reported in a period of 6 months but the rooted layers failed to establish in the field (Deinum 1949). A very low success of $8.5 \%$ was reported in Grenada (Nicholas \& Cruickshank 1964). There are no reports of successful air layering of nutmeg from India.

Taking a cue from the ability of the tree to naturally produce aerial roots, air layering was attempted in nutmeg both in plagiotropic and orthotropic shoots. The study was carried out at the ICAR-Indian Institute of Spices Research Experimental Farms at Chelavoor and Peruvannamuzhi during 2016 \& 2017. The climatic condition was humid-tropical with average temperature ranging between $23{ }^{\circ} \mathrm{C}-$ $32{ }^{\circ} \mathrm{C}$, relative humidity from $60 \%-90 \%$ and average rainfall of $520 \mathrm{~mm}$ during the study period. Air layering was attempted in plagiotropic and orthotropic shoots of 15-30 year old nutmeg trees. A ring of bark at a width of 0.5 $\mathrm{cm}$ was removed from the basal portion of 25-40 $\mathrm{cm}$ long shoots of pencil thickness. The exposed portion was coiled with a jute thread to avoid reunion of the bark and covered with a rooting medium of 1:1 moist soil and coir pith and wrapped with a transparent polythene cover (Fig. 1). Sufficient moisture was provided to the medium periodically by injecting water with the help of a syringe through the wrapper. Out of the 20 twigs layered (10 orthotrops and 10 plagiotrops) during the month of November 2016, root initiation was observed in eight plagiotropic shoots, in the periphery of the canopy in about 90-96 days. All the layered shoots inside the thick, heavily shaded canopy failed to root or the shoot above the ringed portion which gradually dried up suggesting the

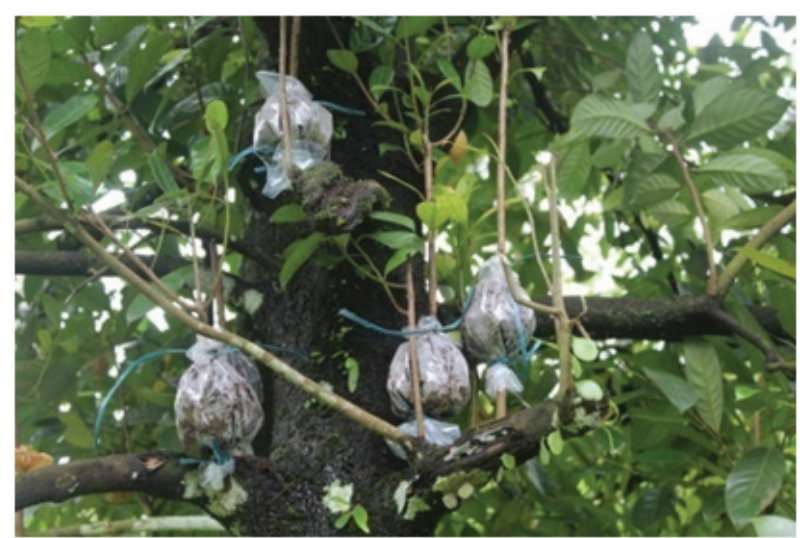

Fig. 1. Air layering in orthotropic shoots

role of sun light in rooting success of the layers. All the orthotropic shoots failed to root as the shoots chosen for layering were in the inner strata of the canopy. This observation was further verified during July 2017 by selecting more orthotropic shoots exposed to good sunlight and $100 \%$ rooting was observed within three months in such twigs (Table 1). There was no significant difference between orthotropic and plagiotropic shoots in days taken for rooting and number of primary roots (Table 2).

The process of layering is the removal of the bark, cambium, and phloem, maintaining the xylem. This prevents downward flow of carbohydrates and photosynthates through phloem but allows water and mineral nutrients to flow upward to the leaves through xylem. Because of this the carbohydrates and photosynthates flowing through the phloem accumulates at the girdling site. The excess of carbohydrates and auxins at the girdling site in presence of moisture induces rooting. The importance of light and photosynthetic activity for rooting success, speed of rooting, and the number of roots produced per cutting was reported in Eucalyptus (Hoad \& Leakey 1996). The earlier reports of failure in

Table 1. Effect of sunlight on rooting success in air layering of nutmeg

\begin{tabular}{|c|c|c|c|c|c|c|c|c|}
\hline \multirow[b]{3}{*}{ Season } & \multicolumn{4}{|c|}{ Sunlight exposed area } & \multicolumn{4}{|c|}{ Heavily shaded area } \\
\hline & \multicolumn{2}{|c|}{ Orthotrops } & \multicolumn{2}{|c|}{ Plagiotrops } & \multicolumn{2}{|c|}{ Orthotrops } & \multicolumn{2}{|c|}{ Plagiotrops } \\
\hline & $\begin{array}{l}\text { shoots } \\
\text { layered }\end{array}$ & $\begin{array}{l}\text { shoots } \\
\text { rooted }\end{array}$ & $\begin{array}{l}\text { shoots } \\
\text { layered }\end{array}$ & $\begin{array}{l}\text { shoots } \\
\text { rooted }\end{array}$ & $\begin{array}{l}\text { shoots } \\
\text { layered }\end{array}$ & $\begin{array}{l}\text { shoots } \\
\text { rooted }\end{array}$ & $\begin{array}{l}\text { shoots } \\
\text { layered }\end{array}$ & $\begin{array}{l}\text { shoots } \\
\text { rooted }\end{array}$ \\
\hline November 2016 & 4 & 4 & 4 & 4 & 6 & 0 & 6 & 0 \\
\hline July 2017 & 5 & 5 & 5 & 5 & 5 & 0 & 5 & 0 \\
\hline
\end{tabular}


Table 2. Comparison of rooting in orthotropic and plagiotropic shoots of nutmeg

\begin{tabular}{lcccccccc}
\hline & \multicolumn{2}{c}{ Days taken for root initiation } & & \multicolumn{2}{c}{ Percentage of rooting } & & \multicolumn{2}{c}{ Number of primary roots } \\
\cline { 2 - 3 } Season & Plagiotrops & Orthotrops & & Plagiotrops & Orthotrops & & Plagiotrops & Orthotrops \\
\hline November 2016 & $90-96$ & Not rooted $^{*}$ & & 80 & $0^{*}$ & & 4.5 & - \\
July 2017 & $84-94$ & $81-92$ & & 100 & 100 & & 4.25 & 4.14
\end{tabular}

*The orthotrops were not rooted as the shoots selected were in the heavily shaded area
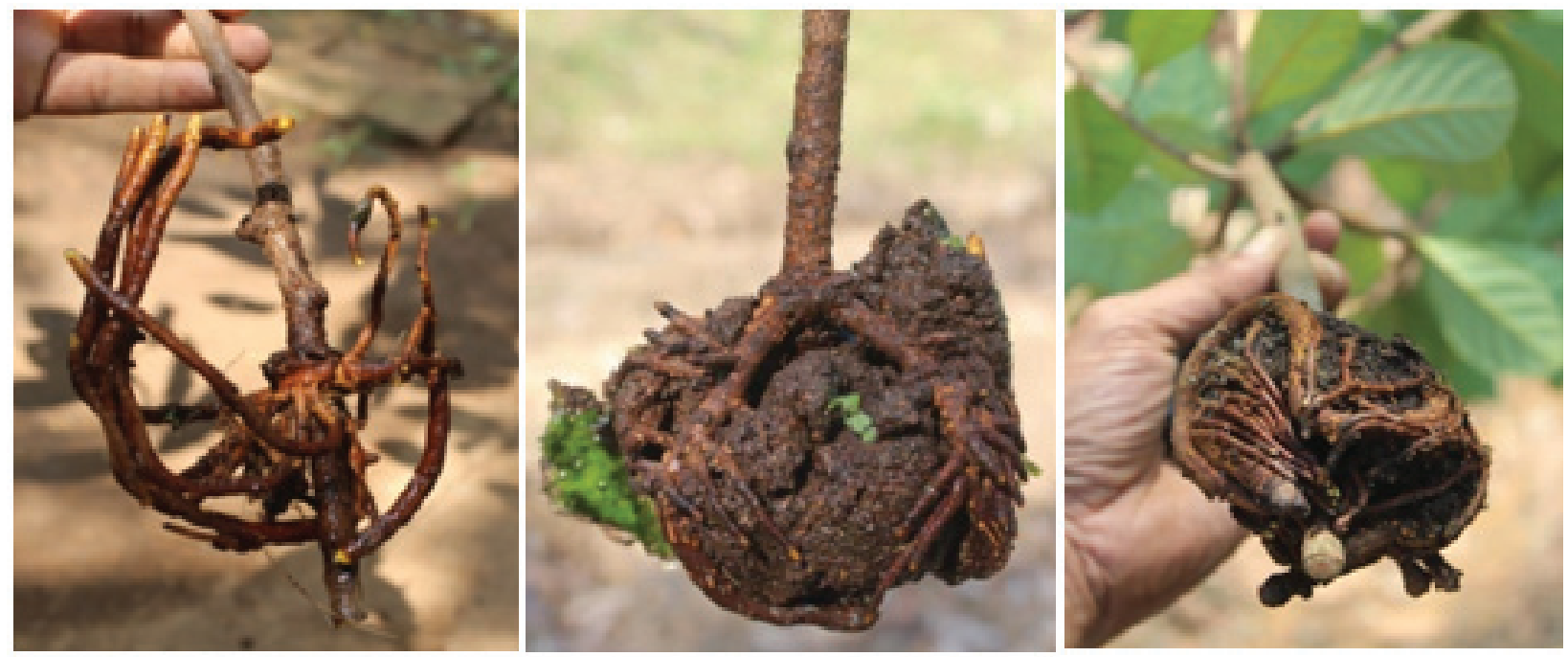

Fig. 2. Various stages of root development

air layering of nutmeg may be due to lack of proper selection of shoots from the dense tree canopy. Generally, the bearing nutmeg trees possess tall and dense canopy, which prevents light penetration to the lower branches. The lower branches, irrespective of their position in the canopy, are usually selected for layering, the primary concern being accessibility of the shoot. The stock plant 'environment 'is known to affect the success of rooting (Leakey 2014).

The root initials were very thick (Fig. 2) and grew rapidly producing profuse thinner secondary and tertiary roots within a month. The rooted twigs were detached from the trees after four months, planted in polythene bags and hardened inside a humid chamber for 20-30 days. The layers were maintained for another one month in nursery after taking out from the hardening chamber and planted in the field (Fig. 3). All the air layered plants established well in the field, showed normal growth and it is under further observation for growth and yield.

This is the first report of successful air layering



Fig. 3. Established orthotropic layers

in nutmeg from India. The study suggests the potential of air layering in nutmeg as an alternative propagation method and we need to have either de-topped mother trees or trees with thinned out canopy so as to enhance the success rate of marcotting.

\section{Acknowledgement}

The authors would like to record gratitude to the Director, ICAR-Indian Institute of Spices Research, Kozhikode for providing the facilities. 


\section{References}

Deinum H 1949 Nootmuskaat en foelie. Landb.i.d. Ind. Arch. D12b: 655683.

Hoad S P \& Leakey R R B 1996 Effects of preseverance light quality on the vegetative propagation of Eucalyptus grandis. Cutting morphology, gas exchange and carbohydrate status during rooting. Trees 10: 317-324.
Leakey R R B 2014 Plant cloning: Macro-propagation In: Van Alfen $\mathrm{N}$ et al. (Ed.) Encyclopedia of Agriculture and Food Systems, Vol 4 (pp.349359), Elsevier Publishers, San Diego

Nichols R \& Cruickshank A M 1964 Vegetative propagation of nutmeg (Myristica fragrans) in Grenada, West Indies. Trop. Agri. (Trin.) 41: 141-146. 